\title{
Clinical significance of preoperative nutritional parameter and patient outcomes after pancreatectomy: A retrospective study at two academic institute
}

\author{
Atsushi Nanashima ${ }^{1,2}$, Masahide Hiyoshi ${ }^{1}$, Naoya Imamura ${ }^{1}$, Koichi Yano ${ }^{1}$, Takeomi Hamada ${ }^{1}$, \\ Rouko Hamada ${ }^{1}$, Kenzo Nagatomo', Makoto Ikenoue ${ }^{1}$, Shuichi Tobinaga ${ }^{2}$, and Takeshi Nagayasu ${ }^{2}$ \\ ${ }^{1}$ Division of Hepato-Biliary-Pancreas Surgery, University of Miyazaki Faculty of Medicine, Miyazaki, \\ ${ }^{2}$ Department of Surgical Oncology, Nagasaki University School of Biomedical Sciences, Nagasaki, Japan
}

\begin{abstract}
Backgrounds/Aims: Preoperative nutritional status has been reported to influence patient outcomes after pancreatectomy. The Prognostic Nutritional Index (PNI) is a useful parameter to reflect the outcomes of patients undergoing gastrointestinal surgery. Therefore, the relationship between the PNI and clinicopathological factors, surgical data, and postoperative morbidity were retrospectively evaluated at two academic institutes in a cohort study. Methods: Curative pancreatectomy was performed on 222 patients at the University of Nagasaki between 1995 and March 2015, and 101 at the University of Miyazaki between April 2015and March 2018. The PNI was calculated using preoperative albumin and total cholesterol levels. Results: The mean PNI in our series was $39.2 \pm 5.4$ and the prevalence of PNIs less than 40 was observed in 134 patients (44\%). The PNI was not significantly different between normal, hard, and fatty architecture of the pancreatic parenchyma. The PNIs were significantly negatively correlated with higher age $(p<0.01)$, but not with gender, co-morbidity, or habits. The PNI was significantly correlated with levels of hemoglobin, prothrombin activity, choline esterase, total protein, albumin and cholesterol $(p<0.01)$, and with postoperative total protein and albumin levels $(p<0.05)$. Although the preoperative PNI tended to be lower in patients with total postoperative complications, no significant differences for each complication were observed. Conclusions: Although the preoperative PNIs reflect the perioperative nutritional status, its predictive usefulness for postoperative complications could not be significantly confirmed. (Ann Hepatobiliary Pancreat Surg 2019;23:168-173)
\end{abstract}

Key Words: Prognostic nutritional index; Pancreatectomy; Postoperative nutritional parameters; Postoperative complications

\section{INTRODUCTION}

Perioperative management and recent advances in surgical techniques for pancreatectomies have provided improved patient outcomes. ${ }^{1,2}$ Although the mortality rate has remarkably decreased, the postoperative morbidity rate is still high compared to other gastrointestinal surgeries. ${ }^{3,4}$ Furthermore, patients with peri-pancreatic malignancies or accompanying pancreatic injury due to pancreatic juice obstruction, have low nutritional statuses. Various prognostic nutritional indices (PNIs) have been proposed and Onodera's PNI proposed in 1984 has often been applied in the field of gastrointestinal surgeries in Japan to predict operative risk. $^{5-9}$ In Onodera's PNI, less than 40 or 45 indicates the severity of a patient's status and their complications after surgery ${ }^{6}$ however, the clinical significance of this index in pancreatectomies has not yet been fully elucidated. We hypothesized that Onodera's PNI was closely related to perioperative patient demographics, surgical data, and short-term outcomes.

The aim of the present study was to determine the predictive significance of the PNI on the outcomes of patients with various diseases after pancreaticoduodenectomy (PD) or distal pancreatectomy. The relationship between the PNI and clinicopathological factors, surgical data, and post-pancreatectomy complications in 323 consec-

Received: November 15, 2018; Revised: December 14, 2018; Accepted: December 15, 2018

Corresponding author: Atsushi Nanashima

Division of Hepato-Biliary-Pancreas Surgery, Department of Surgery, University of Miyazaki Faculty of Medicine, 5200 Kihara Kiyotake, Miyazaki, 889-1692 Japan

Tel: +81-985-85-2905, Fax: +81-985-85-3780, E-mail: a_nanashima@med.miyazaki-u.ac.jp

Copyright (C) 2019 by The Korean Association of Hepato-Biliary-Pancreatic Surgery

This is an Open Access article distributed under the terms of the Creative Commons Attribution Non-Commercial License (http://creativecommons.org/ licenses/by-nc/4.0) which permits unrestricted non-commercial use, distribution, and reproduction in any medium, provided the original work is properly cited. Annals of Hepato-Biliary-Pancreatic Surgery • pISSN: 2508-5778 - elSSN: 2508-5859 
utively selected patients who underwent elective pancreatectomies at two academic institutes, performed by the first author between 1995 and 2018 was investigated.

\section{PATIENTS AND METHODS}

\section{Patients}

The clinical records of 222 consecutively selected patients undergoing pancreatectomies at the Department of Surgical Oncology at the University of Nagasaki School of Biomedical Sciences between 1995 and March 2015, and 101 patients at the Division of Hepato-biliary-pancreas Surgery, Department of Surgery at the University of Miyazaki Faculty of Medicine between April 2015 and March 2018 were collected. The patients' in-hospital data was also collected during follow-up periods. There were no patient selection or matching criteria and all patients were enrolled in the present study. Informed consent for data collection and the use of hemostatic devices was obtained from each patient prior to enrollment. The study design was approved by the ethics review board at our institution. Data were retrieved from both anesthetic and patient charts for our database. On the basis of the Declaration of Helsinki 2013, the study design was approved by the Ethics Committees of both the Nagasaki University Hospital (\#18082008 on August 21, 2018) and the University of Miyazaki Faculty of Medicine (\#O-0341 on May 16, 2018). Informed consent was obtained by an opt-out procedure at each institute for approximately one month according to the planning documents of the study. There was no financial support or conflict of interest regarding the present study.

The mean age for patients at the time of surgery was $65.9 \pm 12.4$ years (range, $14-87$ years). The study included 202 males and 121 females. Accompanying main pancreatic duct obstruction or chronic pancreatitis was present in 99 patients $(31 \%)$, fatty soft pancreas in nine $(3 \%)$, and normal pancreas in 215 patients (67\%). Diseases included pancreatic carcinoma (PC) in 123 patients (38\%), bile duct carcinoma $(\mathrm{BC})$ in $59(18 \%)$, intraductal papillary mucin-producing neoplasms including carcinoma in 41 (13\%), ampullary carcinoma in $33(10 \%)$, gallbladder carcinoma in five $(1 \%)$, duodenal malignancies in $13(4 \%)$, neuroendocrine neoplasms in nine $(3 \%)$, and other diseases in 11 patients $(3 \%)$. The procedures performed in- cluded PD ( $\mathrm{n}=229,71 \%)$, distal pancreatectomy $(\mathrm{n}=76$, $24 \%$ ), and other pancreatic resections were performed in 18 patients $(5 \%)$. Pancreaticojejunostomy was performed in 204 patients and pancreaticogastrostomy was performed in 25 patients undergoing PD. Combined resections of adjacent major vessels were performed in 16 patients $(5 \%)$. Radical pancreatectomy was performed to remove hepatic tumors without leaving any residual tumor in patients with malignancies.

\section{Operative indications, evaluated parameters, surgical procedures}

The indications for pancreatectomy and the types of surgical procedures were determined according to the tumor locations. We examined preoperative clinical parameters, operative procedures, surgical records, and postoperative morbidities. We performed resections using electrocautery, vessel sealing devices, or ultrasonic coagulation devices. Harmonic ultrasonic surgical devices were used for the transections (Ehicon Endo-Surgery Inc., Cincinnati, OH) or Sonosurg (Olympus, Tokyo, Japan). Pancreatectomies were performed by two attending surgeons for 243 operations and resident training surgeons in 80 cases. In the case of trainees, quality control of the operation was provided by attending surgeons. Autologous blood transfusions were not used in any patients in the present study. Intraoperative blood transfusions with red blood cells were performed when unstable vital signs or hemoglobin values of less than $9.0 \mathrm{mg} / \mathrm{dl}$ were observed. Onodera's PNI was calculated using the formula as follows: $10 \times$ serum albumin value $(\mathrm{g} / \mathrm{dl})+0.005 \times$ total lymphocyte count $\left(/ \mathrm{mm}^{3}\right)$ in peripheral blood.

\section{Statistical analysis}

Chi-squared tests were used to compare categorical variables. Differences between the groups were analyzed by Fisher's exact tests and Scheffe's multiple comparison tests. All continuous data were expressed as mean \pm SD. Data for the different groups were compared using oneway analysis of variance and examined by Student's t-test. Logistic regression analysis was performed to determine the predictive value of the risk factors. Potentially predictive variables were identified using a significance level of $p<0.10$ by univariate analysis and the identified factors were then entered into logistic regression multivariate 
analysis. A two-tailed $p<0.05$ was considered significant. PASW Statistics 18.0.0 for Windows (SPSS Inc., IBM, Chicago, IL) was used for all statistical analyses.

\section{RESULTS}

Patient demographics, laboratory data, surgical data, and outcomes

When accompanied by complications or habits, diabetes was observed in 91 patients (28\%), hypertension in 100 $(31 \%)$, cardiovascular diseases in $20(6 \%)$, respiratory disease in $11(3 \%)$, cerebral disease in five $(2 \%)$, and renal disease in seven $(2 \%)$. Smoking habits were observed in 128 patients (37\%), heavy drinking in $136(42 \%)$, and a history of pancreatitis in 62 patients (19\%). The pancreatic function diagnostic test (BT-PABA) showed $60 \pm 19$ percent. In preoperative laboratory data, the hemoglobin levels were $12 \pm 2 \mathrm{~g} / \mathrm{dl}$, platelet counts $95 \pm 113 \times 10^{4} / \mu \mathrm{l}$, prothrombin activity $95 \pm 17 \%$, creatinine $0.9 \pm 0.8 \mathrm{mg} / \mathrm{dl}$, total protein $6.8 \pm 0.7 \mathrm{~g} / \mathrm{dl}$, albumin $3.9 \pm 0.5 \mathrm{~g} / \mathrm{dl}$, total bilirubin $1.8 \pm 5.6 \mathrm{mg} / \mathrm{dl}$, alkaline phosphatase $441 \pm 445 \mathrm{IU} / \mathrm{L}$, choline esterase $231 \pm 96 \mathrm{IU} / \mathrm{L}$, amylase $140 \pm 205 \mathrm{IU} / \mathrm{L}$, total cholesterol $180 \pm 53 \mathrm{mg} / \mathrm{dl}$, blood sugar $116 \pm 43 \mathrm{mg} / \mathrm{dl}$, and the hemoglobin $\mathrm{A}_{1 \mathrm{C}}$ was $5.9 \pm 1.1$ percent. The PNIs were $39.2 \pm 5.4$. The prevalence of PNIs less than 40 was observed in 134 patients (44\%).

The mean blood loss was $1198 \pm 920 \mathrm{ml}$ (range, 10-6600 $\mathrm{ml}$ ) and the mean red cell blood transfusion was $350 \pm 653$ $\mathrm{ml}$ (maximum range, $4150 \mathrm{ml}$ ), and transfusions were performed in 107 patients (35\%). The mean operative time was 559 \pm 187 minutes (range, 167-1265 minutes). Soft normal architecture of the pancreatic parenchyma was observed in 215 patients (67\%), accompanying pancreatitis in $99(31 \%)$, and fatty or fragile pancreases in nine $(2 \%)$. Dilatation of the main pancreatic duct was observed in 99 patients (29\%). Extended lymphadenectomies were performed in 256 patients (79\%).

The mean duration between surgery and oral intake was $13 \pm 13$ days (range, 2-95 days). The decrease in body weight between surgery and hospital discharge was $3.4 \pm 2.8 \mathrm{~kg}$. Within 28 postoperative days, the lowest total protein and albumin levels were $5.1 \pm 0.7$ and $2.7 \pm 0.5 \mathrm{~g} / \mathrm{dl}$, respectively. The lowest choline esterase and total cholesterol levels were $127 \pm 69 \mathrm{IU} / \mathrm{L}$ and $109 \pm 36 \mathrm{mg} / \mathrm{dl}$, respectively. The highest total bilirubin and amylase levels were $2.2 \pm$
$2.4 \mathrm{mg} / \mathrm{dl}$ and $280 \pm 477 \mathrm{IU} / \mathrm{L}$, respectively. Postoperative complications were observed in 166 patients $(52 \%)$, which included pancreatic fistula Grade B or C by the International Study Group (ISGPS) definition ${ }^{10}$ in 60 patients $(19 \%)$, intra-abdominal infections in $76(14 \%)$, wound infections in $10(3 \%)$, delayed gastric emptying ${ }^{11}$ in 32 $(10 \%)$, intra-abdominal hemorrhages in $10(3 \%)$, increased ascites in $31(10 \%)$, intestinal anastomotic leakage in seven $(2 \%)$, and other complications in 51 patients (16\%). Postoperative hospital deaths occurred in four patients.

Comparison of the pancreatic architecture, laboratory data, and postoperative morbidity are shown in Table 1 . In laboratory data, choline esterase levels in the fatty and fragile pancreas group were significantly higher than in the other two groups $(p<0.01)$. Preoperative serum amylase levels in the hard pancreas group were higher than in the normal pancreas group $(p<0.01)$. The PNIs were not significantly different between the groups. Postoperative laboratory data was not significantly different between the groups. The prevalence of severe grade pancreatic fistulas, related intra-abdominal infections, and abdominal bleeding due to pseudo-aneurysms was significantly higher in the fatty and fragile pancreas group $(p<0.05)$.

\section{Relationship between PNIs and other parameters}

The relationship or correlation between the PNIs and clinical factors, laboratory data, surgical data, and patient outcomes are shown in Table 2. The PNIs were significantly negatively correlated with higher age $(p<0.01)$, but not gender. In preoperative co-morbidity and habits, there was no significant difference in the PNIs. In the preoperative laboratory data, the PNIs were significantly correlated with hemoglobin, prothrombin activity, choline esterase levels, total protein and albumin levels, and total cholesterol levels $(p<0.01)$. In patients undergoing PD, the PNIs were significantly higher than in patients with other pancreatectomies $(p<0.05)$. In the postoperative laboratory data, the PNIs were significantly correlated with total protein and albumin levels $(p<0.05)$. Although the preoperative PNIs tended to be lower in patients with postoperative complications, this was not significantly different in the absence or presence of each complication. 
Table 1. Laboratory data and complications in 323 patients

\begin{tabular}{|c|c|c|c|c|}
\hline & $\begin{array}{l}\text { Soft normal pancreas } \\
\qquad(\mathrm{n}=215)\end{array}$ & $\begin{array}{l}\text { Hard pancreas due to } \\
\text { accompanied pancreatitis or } \\
\text { chronic pancreatitis }(n=99)\end{array}$ & $\begin{array}{l}\text { Fatty and fragile } \\
\text { pancreas }(n=9)\end{array}$ & $\begin{array}{l}\text { Significance } \\
\text { ( } p \text {-value })\end{array}$ \\
\hline \multicolumn{5}{|l|}{ Functional liver parameters } \\
\hline Hemoglobin $(\mathrm{g} / \mathrm{dl})$ & $12.2 \pm 2.3$ & $12.2 \pm 1.9$ & $13.3 \pm 1.9$ & \\
\hline Platelet count $\left(10^{4} / \mathrm{ml}\right)$ & $23 \pm 8$ & $23 \pm 8$ & $20 \pm 7$ & \\
\hline Prothrombin activity (\%) & $96 \pm 17$ & $94 \pm 17$ & $89 \pm 16$ & \\
\hline Creatinine $(\mathrm{mg} / \mathrm{dl})$ & $0.9 \pm 0.9$ & $0.8 \pm 0.2$ & $0.8 \pm 0.2$ & \\
\hline Total protein $(\mathrm{g} / \mathrm{dl})$ & $6.8 \pm 0.7$ & $6.8 \pm 0.6$ & $7.0 \pm 0.8$ & \\
\hline Albumin $(\mathrm{g} / \mathrm{dl})$ & $3.9 \pm 0.6$ & $3.8 \pm 0.5$ & $3.9 \pm 0.5$ & \\
\hline Total bilirubin (mg/dl) & $1.8 \pm 6.7$ & $2.0 \pm 2.4$ & $1.1 \pm 0.8$ & \\
\hline Choline esterase (IU/L) & $228 \pm 92$ & $225 \pm 98$ & $338 \pm 120^{*}$ & \\
\hline Amylase (IU/L) & $113 \pm 124$ & $206 \pm 320 * *$ & $83 \pm 35$ & \\
\hline Total cholesterol (mg/dl) & $183 \pm 57$ & $172 \pm 45$ & $188 \pm 44$ & \\
\hline Hemoglobin $A_{1 c}(\%)^{\#}$ & $5.8 \pm 1.1$ & $6.1 \pm 1.0$ & $6.3 \pm 1.4$ & \\
\hline PNI & $39.4 \pm 5.7$ & $38.9 \pm 4.8$ & $39.8 \pm 5.4$ & \\
\hline \multicolumn{5}{|l|}{ Postoperative function within 28 days } \\
\hline Total protein $(\mathrm{g} / \mathrm{dl})$ & $5.1 \pm 0.8$ & $5.0 \pm 0.7$ & $4.9 \pm 0.6$ & \\
\hline Albumin $(\mathrm{g} / \mathrm{dl})$ & $2.7 \pm 0.5$ & $2.7 \pm 0.5$ & $2.4 \pm 0.4$ & \\
\hline Total bilirubin (mg/dl) & $2.0 \pm 2.1$ & $2.7 \pm 2.9$ & $2.2 \pm 1.4$ & \\
\hline Choline esterase (IU/L) & $276 \pm 371$ & $300 \pm 671$ & $180 \pm 260$ & \\
\hline Total cholesterol (mg/dl) & $111 \pm 40$ & $107 \pm 30$ & $98 \pm 5$ & \\
\hline \multicolumn{5}{|l|}{ Postoperative morbidity } \\
\hline Total (no/yes) & $101 / 114(53)$ & $53 / 46(48)$ & $3 / 6(67)$ & $p=0.510$ \\
\hline Pancreatic fistula BC (no/yes) & $171 / 44(21)$ & $87 / 12(13)$ & $5 / 4(44)$ & $p=0.033$ \\
\hline Intra-abdominal infection (no/yes) & $161 / 54(25)$ & 79/16 (17) & $3 / 6(69)$ & $p<0.01$ \\
\hline Wound infection (no/yes) & $207 / 8(4)$ & $93 / 2(2)$ & $9 / 0(0)$ & $p=0.651$ \\
\hline Abdominal bleeding (no/yes) & $210 / 5(2)$ & $92 / 3(3)$ & $7 / 2(22)$ & $p<0.01$ \\
\hline Long-term ascites (no/yes) & 197/18 (8) & $84 / 11(12)$ & $7 / 2(22)$ & $p=0.297$ \\
\hline Delayed gastric empty (no/yes) & 194/21 (10) & 84/11 (11) & $9 / 0(0)$ & $p=0.525$ \\
\hline Anastomotic leakage (no/yes) & 208/7 (3) & $95 / 0(0)$ & $9 / 0(0)$ & $p=0.178$ \\
\hline Others (no/yes) & $183 / 32(15)$ & 77/18 (19) & $8 / 1(11)$ & $p=0.609$ \\
\hline
\end{tabular}

PNI, Prognostic Nutritional Index

Continuous data are shown as the mean \pm SD. Parenthesis showed a range of minimum and maximum value Parenthesis showed the percentage rate of presence ofthe complication

${ }^{*} p<0.01$ vs. other group, ${ }^{* *} p<0.01$ vs. soft normal group, ${ }^{\#}$ the number of subject was 159,81 and 8 , respectively

\section{DISCUSSION}

Preoperative poor nutritional status has been related to operative risk with respect to increased morbidity rates in digestive surgeries. ${ }^{12-14}$ Therefore, we attempted to improve the nutritional status by monitoring nutritional parameters, calorie increases, and the administration of enteral nutritional products. The comprehensive index or parameters to evaluate nutrition or predict operative risks have been reported worldwide..$^{5-9,15,16}$ The PNI was first proposed by Lowe ${ }^{5}$ and subsequently, Onodera et al. ${ }^{6}$ proposed a modified PNI in a Japanese patient series. These PNIs well-reflected the patient risk with respect to morbidity or mortality in gastrointestinal surgery. ${ }^{6-9}$ Pancreat- ectomy, particularly PD, is a high-risk operation compared to gastrectomies or colectomies because of its increased invasiveness. ${ }^{3,4}$ Mortality and morbidity were still important concerns in some patients. Furthermore, patients with malignant diseases who undergo pancreatectomies often show poor nutritional statuses due to decreased exocrine or endocrine functions, obstructive jaundice, or advances of the malignant behavior of the disease itself. ${ }^{17}$ To our knowledge, the relationship between the nutritional status or its management and postoperative outcomes after pancreatectomy has not been examined. The PNI can be calculated with a simple formula using albumin and the total lymphocyte count. ${ }^{6}$ Postoperatively, alterations in nutritional status or in the PNIs have been associated with 
Table 2. Relationship between PNIs and clinico-pathological parameters

\begin{tabular}{|c|c|}
\hline Age & $\mathrm{r}=-0.178^{* *}$ \\
\hline \multicolumn{2}{|l|}{ Gender } \\
\hline Male $(n=202)$ & $39.0 \pm 5.3$ \\
\hline Female $(\mathrm{n}=121)$ & $39.7 \pm 5.7$ \\
\hline Diabetes (no/yes) $(n=226 / 91)$ & $39.3 \pm 5.5 / 39.2 \pm 5.3$ \\
\hline Smoker (no/yes) $(\mathrm{n}=196 / 118)$ & $39.3 \pm 5.6 / 39.2 \pm 5.2$ \\
\hline Heavy drinker (no/yes) $(n=178 / 136)$ & $39.3 \pm 5.6 / 39.2 \pm 5.2$ \\
\hline History of pancreatitis (no/yes) $(\mathrm{n}=255 / 62)$ & $39.2 \pm 5.6 / 39.5 \pm 4.5$ \\
\hline \multicolumn{2}{|l|}{ Functional parameters } \\
\hline Hemoglobin (g/dl) & $\mathrm{r}=0.346^{* *}$ \\
\hline Platelet count $\left(/ \mathrm{mm}^{3}\right)$ & $\mathrm{r}=-0.115$ \\
\hline Prothrombin activity (\%) & $\mathrm{r}=0.251 * *$ \\
\hline Total bilirubin (mg/dl) & $\mathrm{r}=-0.121$ \\
\hline Choline esterase (IU/L) & $\mathrm{r}=0.321 * *$ \\
\hline Creatinine $(\mathrm{mg} / \mathrm{dl})$ & $\mathrm{r}=-0.030$ \\
\hline Total protein $(\mathrm{g} / \mathrm{dl})$ & $\mathrm{r}=0.669 * *$ \\
\hline Albumin $(\mathrm{g} / \mathrm{dl})$ & $\mathrm{r}=-0.995^{* *}$ \\
\hline Amylase (IU/L) & $\mathrm{r}=-0.100$ \\
\hline Total cholesterol (mg/ml) & $\mathrm{r}=0.264 * *$ \\
\hline Hemoglobin $A_{1 C}(\%)$ & $\mathrm{r}=-0.048$ \\
\hline \multicolumn{2}{|l|}{ Surgical record } \\
\hline $\begin{array}{l}\text { Pancreaticoduodenectomy/ } \\
\text { others }(n=99 / 224)\end{array}$ & $40.1 \pm 6.2 / 38.9 \pm 5.1^{*}$ \\
\hline Operation time (minutes) & $\mathrm{r}=-0.053$ \\
\hline Blood loss (ml) & $\mathrm{r}=-0.120^{*}$ \\
\hline \multicolumn{2}{|l|}{ Postoperative functional parameters $\$$} \\
\hline Total protein $(\mathrm{g} / \mathrm{dl})$ & $\mathrm{r}=0.127^{*}$ \\
\hline Albumin $(\mathrm{g} / \mathrm{dl})$ & $\mathrm{r}=0.326^{* *}$ \\
\hline Total bilirubin level (mg/dl) & $\mathrm{r}=-0.092$ \\
\hline Choline esterase (IU/L) & $\mathrm{r}=-0.109$ \\
\hline Total cholesterol (IU/L) & $\mathrm{r}=-0.105$ \\
\hline Amylase (IU/L) & $\mathrm{r}=-0.011$ \\
\hline Duration of oral intake (days) & $\mathrm{r}=-0.047$ \\
\hline Decreased body weight $(\mathrm{kg})$ & $\mathrm{r}=-0.030$ \\
\hline $\begin{array}{l}\text { Postoperative total complications } \\
\text { (no/yes) }(\mathrm{n}=157 / 166)\end{array}$ & $39.9 \pm 5.2 / 38.7 \pm 5.6^{\#}$ \\
\hline $\begin{array}{l}\text { Pancreatic fistula grade BC } \\
\text { (no/yes) }(n=263 / 60)\end{array}$ & $39.4 \pm 5.1 / 38.9 \pm 6.6$ \\
\hline $\begin{array}{l}\text { Intra-abdominal infection } \\
(\text { no/yes })(n=247 / 76)\end{array}$ & $39.4 \pm 5.3 / 38.9 \pm 6.0$ \\
\hline Wound infection (no/yes) $(\mathrm{n}=313 / 10)$ & $39.3 \pm 5.5 / 37.7 \pm 3.9$ \\
\hline Abdominal bleeding (no/yes) $(n=313 / 10)$ & $39.3 \pm 5.5 / 38.2 \pm 5.2$ \\
\hline Ascites or chyle-leak (no/yes) $(n=292 / 31)$ & $39.3 \pm 5.5 / 38.8 \pm 4.9$ \\
\hline $\begin{array}{l}\text { Delayed gastric empty } \\
\text { (no/yes) }(n=316 / 32)\end{array}$ & $39.4 \pm 5.4 / 37.8 \pm 5.4$ \\
\hline Intestinal leakage (no/yes) $(n=316 / 7)$ & $39.2 \pm 5.5 / 40.7 \pm 4.7$ \\
\hline Others (no/yes) $(n=272 / 51)$ & $39.4 \pm 5.5 / 38.7 \pm 4.9$ \\
\hline
\end{tabular}

PNI, Prognostic Nutritional Index

Continuous data are shown as the mean \pm SD

$\mathrm{R}$, Pearson's correlation co-efficient

Categorical data were examined by chi-square test ${ }^{*} p<0.05,{ }^{* *} p<0.01,{ }^{*} p=0.072,{ }^{\text {S }}$ maximum or minimum value within 28 days after pancreatectomy complications or administrative costs. ${ }^{18-21}$ Recent improvements in the operative results of patients undergoing liver or pancreatic surgery might be caused by better nutritional management. ${ }^{21}$ Scoring systems reflecting the clinical significance have not yet been applied. To achieve successful results for such patients, preoperative nutritional management is often required.

In the present study, we first examined the nutritional parameters or postoperative complications in each pancreatic architecture enhanced by duct obstruction or obesity. In previous studies, a soft pancreas or small pancreatic duct size was significantly associated with pancreatic fistula. ${ }^{22}$ Furthermore, in our experience, a fatty pancreas with fragility was associated with a higher risk of fistulas. Higher choline esterase levels correlated with fatty changes, and an excessive nutritional status might enhance such a condition. Preoperative pancreatic inflammation correlated with preoperative amylase levels. Otherwise, there were no remarkable differences in the parameters between the groups. Thus, it is still difficult to evaluate the status of the pancreatic architecture form the preoperative blood parameters, including the PNIs. Contrary to previous reports, ${ }^{22,23}$ there was no difference in morbidity between patients with a normal soft pancreas and those with a hard pancreas with chronic inflammation in our series. However, fatty changes of the pancreas increased the morbidity risk.

To determine the clinical significance of the PNI results, we next examined the correlation between demographics, surgical data, and postoperative outcomes, although such a correlation could not be fully conducted. Younger age was correlated with higher PNIs, as expected. Contrary to our expectation, the PNIs in patients with or without diabetes, alcoholism, and pancreatitis were not different, and the mean value of the PNI was set near 39, a value similar to the cut-off level of PNIs for postoperative morbidity in gastrointestinal surgeries in previous reports. ${ }^{7-9}$ Preoperative PNIs correlated with other nutritional parameters. however, the PNIs were not correlated with serum amylase levels reflective of pancreatic inflammation. Thus, prediction of the pancreatic architecture and related surgical data were difficult by these nutritional parameters. Shi et al. ${ }^{18}$ reported that impaired glucose tolerance levels and decreased albumin levels were associated with morbidity. If postoperative func- 
tional parameters are correlated with preoperative data, the preoperative function is supposed to predict the postoperative function and related complications. The study results showed that only total protein and albumin levels were correlated with the PNIs. Decreased levels of these parameters were not associated with morbidity (data was not shown). The PNI levels between each complication were not different however, the presence of comprehensive complications tended to show lower preoperative PNIs (less than 39). As in previous reports, a cut-off level of PNI 40 was reasonable to predict operative risk however, the clinical significance level was not high and establishment as a predictive factor was difficult. Therefore, use of the new or modified prognostic nutritional index for pancreatectomy only should be the next step.

In conclusion, we examined the preoperative PNI levels and association with other demographics, nutritional or organ parameters, surgical data, and postoperative complications in a retrospective analysis using the clinical records of 323 patients who underwent elective pancreatectomies for peripancreatic diseases at two academic cancer institutes. The PNIs were not associated with pancreatic architecture, known to be associated with postoperative complications. The PNIs correlated with preoperative metabolic parameters and postoperative protein and albumin levels but were not different in the presence or absence of each complication. Use of a more sensitive PNI using the modified formula specific to pancreatic surgery is necessary.

\section{REFERENCES}

1. Donahue TR, Reber HA. Pancreatic surgery. Curr Opin Gastroenterol 2010;26:499-505.

2. Niedergethmann M, Farag Soliman M, Post S. Postoperative complications of pancreatic cancer surgery. Minerva Chir 2004; 59:175-183.

3. Jilesen AP, van Eijck $\mathrm{CH}$, in't Hof $\mathrm{KH}$, van Dieren S, Gouma DJ, van Dijkum EJ. Postoperative complications, in-hospital mortality and 5-year survival after surgical resection for patients with a pancreatic neuroendocrine tumor: a systematic review. World J Surg 2016;40:729-748.

4. Lermite E, Sommacale D, Piardi T, Arnaud JP, Sauvanet A, Dejong $\mathrm{CH}$, et al. Complications after pancreatic resection: diagnosis, prevention and management. Clin Res Hepatol Gastroenterol 2013;37:230-239.

5. Lowe EF, Stein M, Woolley T, Waycaster M, Scroggins B, Acuff R, et al. Prognostic nutritional index: its usefulness as a predictor of clinical course. J Am Coll Nutr 1983;2:231-240.

6. Onodera T, Goseki N, Kosaki G. [Prognostic nutritional index in gastrointestinal surgery of malnourished cancer patients]. Nihon Geka Gakkai Zasshi 1984;85:1001-1005. Japanese.

7. Pinato DJ, North BV, Sharma R. A novel, externally validated inflammation-based prognostic algorithm in hepatocellular carcinoma: the prognostic nutritional index (PNI). Br J Cancer 2012; 106:1439-1445.

8. Nozoe T, Ninomiya M, Maeda T, Matsukuma A, Nakashima H, Ezaki T. Prognostic nutritional index: a tool to predict the biological aggressiveness of gastric carcinoma. Surg Today 2010; 40:440-443.

9. Jiang N, Deng JY, Ding XW, Ke B, Liu N, Zhang RP, et al. Prognostic nutritional index predicts postoperative complications and long-term outcomes of gastric cancer. World J Gastroenterol 2014;20:10537-10544.

10. Harnoss JC, Ulrich AB, Harnoss JM, Diener MK, Büchler MW, Welsch T. Use and results of consensus definitions in pancreatic surgery: a systematic review. Surgery 2014;155:47-57.

11. Park JS, Hwang HK, Kim JK, Cho SI, Yoon DS, Lee WJ, et al. Clinical validation and risk factors for delayed gastric emptying based on the International Study Group of Pancreatic Surgery (ISGPS) classification. Surgery 2009;146:882-887.

12. Shaw-Stiffel TA, Zarny LA, Pleban WE, Rosman DD, Rudolph RA, Bernstein LH. Effect of nutrition status and other factors on length of hospital stay after major gastrointestinal surgery. Nutrition 1993;9:140-145.

13. Vidal Casariego A, Calleja Fernández A, Villar Taibo R, Urioste Fondo A, Pintor de la Maza B, Hernández Moreno A, et al. Efficacy of enteral nutritional support after hospital discharge in major gastrointestinal surgery patients: a systematic review. Nutr Hosp 2017;34:719-726.

14. Mosquera C, Koutlas NJ, Edwards KC, Strickland A, Vohra NA, Zervos EE, et al. Impact of malnutrition on gastrointestinal surgical patients. J Surg Res 2016;205:95-101.

15. Salehi-Abargouei A, Akbari F, Bellissimo N, Azadbakht L. Dietary diversity score and obesity: a systematic review and meta-analysis of observational studies. Eur J Clin Nutr 2016;70: 1-9.

16. Gao Y, Huang D. The value of the systematic inflammationbased Glasgow Prognostic Score in patients with gastric cancer: a literature review. J Cancer Res Ther 2014;10:799-804.

17. Koretz RL. The evidence for the use of nutritional support in liver disease. Curr Opin Gastroenterol 2014;30:208-214.

18. Shi HJ, Jin C, Fu DL. Impact of postoperative glycemic control and nutritional status on clinical outcomes after total pancreatectomy. World J Gastroenterol 2017;23:265-274.

19. Short MN, Ho V, Aloia TA. Impact of processes of care aimed at complication reduction on the cost of complex cancer surgery. J Surg Oncol 2015;112:610-615.

20. Sato N, Mori Y, Minagawa N, Tamura T, Shibao K, Higure A, et al. Rapid postoperative reduction in prognostic nutrition index is associated with the development of pancreatic fistula following distal pancreatectomy. Pancreatology 2014;14:216-220.

21. Shils ME. Effects on nutrition of surgery of the liver, pancreas, and genitourinary tract. Cancer Res 1977;37:2387-2394.

22. Kawai M, Kondo S, Yamaue H, Wada K, Sano K, Motoi F, et al. Predictive risk factors for clinically relevant pancreatic fistula analyzed in 1,239 patients with pancreaticoduodenectomy: multicenter data collection as a project study of pancreatic surgery by the Japanese Society of Hepato-Biliary-Pancreatic Surgery. J Hepatobiliary Pancreat Sci 2011;18:601-608.

23. Yardimci S, Kara YB, Tuney D, Attaallah W, Ugurlu MU, Dulundu E, et al. A simple method to evaluate whether pancreas texture can be used to predict pancreatic fistula risk after pancreatoduodenectomy. J Gastrointest Surg 2015;19:1625-1631. 